J.P. Fryer, MS

V.A. Lennon, MD, PhD

S.J. Pittock, MD

S.M. Jenkins, MS

P. Fallier-Becker, $\mathrm{PhD}$

S.L. Clardy, MD, PhD

E. Horta, MD

E.A. Jedynak, BS

C.F. Lucchinetti, MD

E.A. Shuster, MD

B.G. Weinshenker, MD

D.M. Wingerchuk, MD

A. McKeon, MD

Correspondence to

Dr. McKeon:

mckeon.andrew@mayo.edu

\title{
AQP4 autoantibody assay performance in clinical laboratory service
}

\section{OPEN}

\section{ABSTRACT}

Objective: To compare performance of contemporary aquaporin-4-immunoglobulin (Ig) G assays in clinical service.

Methods: Sera from neurologic patients (4 groups) and controls were tested initially by service ELISA (recombinant human aquaporin-4, M1 isoform) and then by cell-based fluorescence assays: fixed (CBA, M1-aquaporin-4, observer-scored) and live (fluorescence-activated cell sorting [FACS], M1 and M23 aquaporin-4 isoforms). Group 1: all Mayo Clinic patients tested from January to May 2012; group 2: consecutive aquaporin-4-lgG-positive patients from September 2011 (Mayo and non-Mayo); group 3: suspected ELISA false-negatives from 2011 to 2013 (physician-reported, high likelihood of neuromyelitis optica spectrum disorders [NMOSDs] clinically); group 4: suspected ELISA false-positives (physician-reported, not NMOSD clinically).

Results: Group 1 ( $n=388$ ): M1-FACS assay performed optimally (areas under the curves: $M 1=0.64$; M23 = 0.57 [ $p=0.02]$ ). Group $2(n=30)$ : NMOSD clinical diagnosis was confirmed by: M23-FACS, 24; M1-FACS, 23; M1-CBA, 20; and M1-ELISA, 18. Six results were suspected false-positive: M23-FACS, 2; M1-ELISA, 2; and M23-FACS, M1-FACS, and M1-CBA, 2. Group 3 ( $n=31$, suspected M1-ELISA false-negatives): results were positive for 5 sera: M1-FACS, 5; M23-FACS, 3; and M1-CBA, 2. Group 4 ( $n=41$, suspected M1-ELISA false-positives): all negative except 1 (positive only by M1-CBA). M1/M23-cotransfected cells expressing smaller membrane arrays of aquaporin-4 yielded fewer false- positive FACS results than M23-transfected cells.

Conclusion: Aquaporin-4-transfected CBAs, particularly M1-FACS, perform optimally in aiding NMOSD serologic diagnosis. High-order arrays of M23-aquaporin-4 may yield false-positive results by binding IgG nonspecifically. Neurol Neuroimmunol Neuroinflammation 2014;1:e11; doi: 10.1212/ NXI.0000000000000011

\section{GLOSSARY}

AcGFP = Aequorea coerulescens green fluorescent protein; ANA = antinuclear antibody; AQP4 = aquaporin-4; BSA = bovine serum albumin; $\mathbf{C B A}=$ cell-based assay; $\mathbf{C l}=$ confidence interval; EDTA = ethylenediaminetetraacetic acid; $\mathbf{F A C S}=$ fluorescenceactivated cell sorting; $\mathbf{H E K}=$ human embryonic kidney; Ig = immunoglobulin; $\mathbf{M F I}=$ median fluorescence intensity; $\mathbf{M S}=$ multiple sclerosis; NMOSD = neuromyelitis optica spectrum disorder; $\mathbf{O N}=$ optic neuritis; PBS = phosphate-buffered saline; ROC = receiver operating characteristic; $\mathbf{T M}=$ transverse myelitis.

The diagnosis of neuromyelitis optica spectrum disorders (NMOSDs) relies on accurate determination of aquaporin-4 (AQP4)-immunoglobulin (Ig) G autoantibody status. NMOSDs include relapsing or bilateral optic neuritis $(\mathrm{ON})$, relapsing longitudinally extensive transverse myelitis (TM), and encephalopathies involving circumventricular organs. ${ }^{1,2}$ AQP4-IgG seropositivity distinguishes NMOSD from multiple sclerosis (MS). These disorders differ in pathogenesis, clinical course, treatment recommendations, and prognosis. ${ }^{3,4}$ Detection of AQP4-IgG at the first ON or TM attack justifies consideration of long-term immunosuppression. ${ }^{5,6}$ False-positive serology is potentially detrimental to patient care.

From the Departments of Laboratory Medicine and Pathology (J.P.F., V.A.L., S.J.P., E.H., E.A.J., A.M.), Neurology (V.A.L., S.J.P., S.L.C., C.F.L., B.G.W., A.M.), Immunology (V.A.L.), and Health Sciences Research (S.M.J.), College of Medicine, Mayo Clinic, Rochester, MN; Institute of Pathology and Neuropathology (P. F.-B.), University of Tubingen, Germany; Department of Neurology (E.A.S.), College of Medicine, Mayo Clinic, Jacksonville, FL; and Department of Neurology (D.M.W.), College of Medicine, Mayo Clinic, Scottsdale, AZ.

Go to Neurology.org/nn for full disclosures. Funding information and disclosures deemed relevant by the authors, if any, are provided at the end of the article. The Article Processing Charge was paid by the authors.

This is an open access article distributed under the terms of the Creative Commons Attribution-Noncommercial No Derivative 3.0 License, which permits downloading and sharing the work provided it is properly cited. The work cannot be changed in any way or used commercially. 
The first generation AQP4-IgG assay was tissue-based immunofluorescence, with low sensitivity $(48 \%-54 \%)$ but high specificity for NMOSD diagnosis. ${ }^{5,7}$ International consensus concluded that assays using recombinant AQP4 antigen were more sensitive than tissue-based assays. ${ }^{5-11}$ Specificities of $99 \%-100 \%$ have been reported for recombinant human AQP4 ELISA and transfected cell-based assays (CBAs). ${ }^{5,8-10}$ Our experience has revealed instances of positive results in patients not meeting NMOSD clinical criteria.

Assay methodology influences performance. Cells transfected with the M23-AQP4 isoform have been reported to be a more sensitive substrate for NMOSD diagnosis than M1-AQP4transfected cells. ${ }^{10}$ The M23 isoform lacks the $22 \mathrm{~N}$-terminal residues of M1-AQP4. ${ }^{12} \mathrm{M} 23$ AQP4 is recognized ultrastructurally to exist in plasma membranes of astrocytes ${ }^{13}$ and transfected cells as orthogonal arrays of particles, limited in size when M1-AQP4 is coexpressed. ${ }^{14,15}$

This report describes our 2011-2013 clinical service laboratory experience with M1-ELISA performed in parallel with AQP4-transfected CBAs (both observer-scored immunofluorescence microscopy and fluorescence-activated cell sorting $[\mathrm{FACS}])$. We also investigated the influence of transfecting cells with a mixture of M1 and M23 on FACS performance.

METHODS Standard protocol approvals, registrations, and patient consents. This study was approved by the Mayo Clinic Institutional Review Board.

Control subjects. We evaluated 5 groups of sera (total 338 patients). Two were disease control groups: 158 with a non-NMOSD demyelinating disease and 19 with systemic lupus erythematosus or Sjogren syndrome without neurologic involvement. The remaining 3 serum groups had been submitted by general medical clinics for routine chemistry or serology analyses (no histories available): 40 had no biochemical abnormality, 21 had hypergammaglobulinemia, and 100 were positive for antinuclear antibody (ANA).

Patients whose differential diagnosis included NMOSD. We investigated serum submitted from a total of 1,075 patients for M1-ELISA testing in the course of neurologic evaluation. Clinical information was available for all group 1 patients and for seropositive patients in groups $2-4$. AQP4-IgG test results were analyzed with reference to physician-assigned pretest diagnoses.

Group 1. Group 1 consisted of consecutive Mayo Clinic patients tested from January 1 to May 31, $2012(\mathrm{n}=388)$ who had either (1) clinically defined NMO (meeting Wingerchuk 2006 criteria, ${ }^{16}$ excluding AQP4-IgG seropositivity), (2) potential first presentation of an NMOSD (monophasic or recurrent attack of ON only; monophasic or recurrent attack of TM only [longitudinally extensive or short segment lesions]), or (3) an alternative neurologic diagnosis.
NMO or NMOSD was the suspected pretest diagnosis for 50 patients: NMO (12); ON (10; monophasic unilateral, 7; monophasic bilateral, 2; recurrent, 1); TM (28; monophasic, 21; recurrent, 7). Other neurologic diagnoses were considered more likely pre-test for the remaining 338 patients.

Group 2. Group 2 consisted of consecutive seropositive Mayo Clinic and non-Mayo Clinic patients $(\mathrm{n}=30)$ among 615 sera submitted for AQP4-IgG testing in September 2011.

Group 3 and group 4. Groups 3 and 4 consisted of patients not in group 1 or 2 who came to our attention through clinical service laboratory consultation initiated by referring neurologists (2011-2013). Group 3 comprised potential false-negatives: 31 M1-ELISA-negative patients for whom clinical NMOSD suspicion was high. Group 4 comprised potential false-positives: 41 M1-ELISA-positive patients lacking clinical evidence of NMOSD.

Statistical analyses. Sensitivity and specificity were determined for each assay by reference to pretest diagnoses for group 1 patients. $\mathrm{McNemar}$ or exact binomial tests were used as appropriate to compare interassay sensitivity and specificity differences (JMP version 9.0 and SAS version 9.2 [SAS Institute, Cary, NC]). Receiver operating characteristic (ROC) curves were not generated for M1ELISA or M1-CBA data due to low variability. From ROC curves generated for FACS results, we compared areas under the curves for M1 and M23 FACS results against chance (0.50) and one another. Positive likelihood ratios $\left(\frac{\text { sensitivity }}{[1-\text { specificity }]}\right)$ and confidence intervals $(\mathrm{CIs})$ were calculated for group 1 and 2 patients combined. SAS version 9, JMP version 9, or R software was used for all analyses. ${ }^{17} p$ values $<0.05$ were considered statistically significant.

Assays. For quality assurance, assays were repeated at least once for all sera yielding a positive result. All testing was performed blinded to clinical data.

Live cell-based (FACS) assays. Human embryonic kidney (HEK293) cells were transfected using Effectene (per manufacturer instructions; Qiagen, Valencia, CA) with $3 \mu \mathrm{g}$ plasmid DNA (pIRES2-Aequorea coerulescens green fluorescent protein [AcGFP]/ human AQP4; either M1 or M23, or both at 1:1 ratio). For cotransfection studies, M23-AQP4 was expressed with DsRed as a transfection marker (pIRES2-DsRed/M23-AQP4). Cells were cultured for an additional 36 hours posttransfection and lifted by exposing to $0.25 \%$ trypsin/ethylenediaminetetraacetic acid (EDTA; Invitrogen, Carlsbad, CA) for 2 minutes at room temperature. Subsequent steps were at $4^{\circ} \mathrm{C}$. Washed cells were suspended in phosphate-buffered saline (PBS) containing $0.02 \%$ sodium azide, $\mathrm{pH} 7.2,0.5 \%$ bovine serum albumin (BSA), $2 \mathrm{mM}$ EDTA, and Fc receptor blocking reagent (Miltenyi Biotec, Auburn, CA); rotated for $10 \mathrm{mi}-$ nutes; diluted in PBS (containing 2\% BSA, 10\% normal goat serum, $15 \mathrm{mM}$ EDTA, and $0.05 \%$ sodium azide); and dispensed into 96well round bottom plates $\left(1 \times 10^{5}\right.$ cells/well; Becton Dickinson/ Falcon, Franklin Lakes, NJ). Sera were heat-inactivated (35 minutes at $56^{\circ} \mathrm{C}$ ), diluted in PBS (containing $2 \%$ BSA, $10 \%$ normal goat serum, $15 \mathrm{mM}$ EDTA, and $0.05 \%$ sodium azide), and added to duplicate wells at 1:5 final dilution. After shaking the plates (30 minutes, $300 \mathrm{rpm})$, cells were washed 3 times with PBS. Goat antihuman $\operatorname{IgG}(\gamma$ heavy and light chain-specific, Alexafluor 647-conjugated) was added at 1:500 (diluted in PBS containing 2\% BSA, $10 \%$ normal goat serum, $15 \mathrm{mM} \mathrm{EDTA}$, and $0.05 \%$ sodium azide). After shaking $\left(30\right.$ minutes, $\left.4^{\circ} \mathrm{C}\right)$, cells were washed 3 times with PBS, fixed in $4 \%$ paraformaldehyde (Electron Microscopy Sciences, Hatfield, PA), and analyzed by flow cytometer (LSR II, Becton Dickinson). Two populations were gated on the basis of GFP expression: positive (high AQP4 expression) and negative (low or no AQP4 expression). The median Alexafluor 647 fluorescence intensity (MFI) 
for the GFP-positive population indicated relative abundance of human IgG potentially bound to AQP4 surface epitopes; MFI for the GFP-negative population indicated nonspecifically-bound IgG. The IgG binding index was calculated as the ratio of the average MFI for duplicate aliquots of each cell population: $\frac{\text { MFI GFP-positive }}{\text { MFI GFP-negative }}$

The mean IgG binding index value (plus 2 SDs) for the 338 control subjects' sera was 1.50 for M1-FACS and 2.50 for M23-FACS. We established conservative cutoff IgG binding index values: 2.00 for M1-FACS and 3.00 for M23-FACS.

Sixteen sera that yielded positive results by M23-FACS (14 patients without NMOSD diagnosis, 2 with NMOSD diagnosis) were analyzed further by M1-FACS and by FACS using HEK293 cells transfected with M23-AQP4 alone or dually transfected with both M1-AQP4 and M23-AQP4.

ELISA and fixed cell-based assays. Commercial kit assays (M1AQP4 antigen) were used in the ELISA (RSR Limited, Cardiff, UK) and fixed permeabilized CBA (observer-scored immunofluorescence;
Euroimmun, Lubeck, Germany). ${ }^{5}$ M1-ELISA results were reported in arbitrary units (positive values $=5 \mathrm{U} / \mathrm{mL}$ or greater, per manufacturer). CBA results were reported as positive or negative. Preliminary comparison of Euroimmun M1-CBA and M23-CBA was performed for 60 patients. M1-CBA was chosen for all other tests because the higher background in the M23-CBA hindered interpretation of some sera.

Freeze-fracture and Western blot analyses of membranous M1 and M23 recombinant AQP4 proteins. Plasma membranes of transfected HEK293 cells were examined by freeze-fracture electron microscopy. ${ }^{18}$ Briefly, cells were fixed with $2.5 \%$ glutaraldehyde in $0.1 \mathrm{M}$ cacodylate buffer, quick frozen in nitrogen slush $\left(-210^{\circ} \mathrm{C}\right)$, and fractured (BAF400D, Balzers, Liechtenstein). Replicas were achieved by shadowing samples with platin and carbon followed by digestion of residual cell material.

For Western blot, HEK293 cells transfected with pIRES2AcGFP/human M1-AQP4, pIRES2-DsRed/human M23AQP4, or both (1:1 ratio) were lysed at $4^{\circ} \mathrm{C}$ in NativePAGE

Figure 1 Examples illustrating gating strategy for fluorescence-activated cell sorting (FACS)
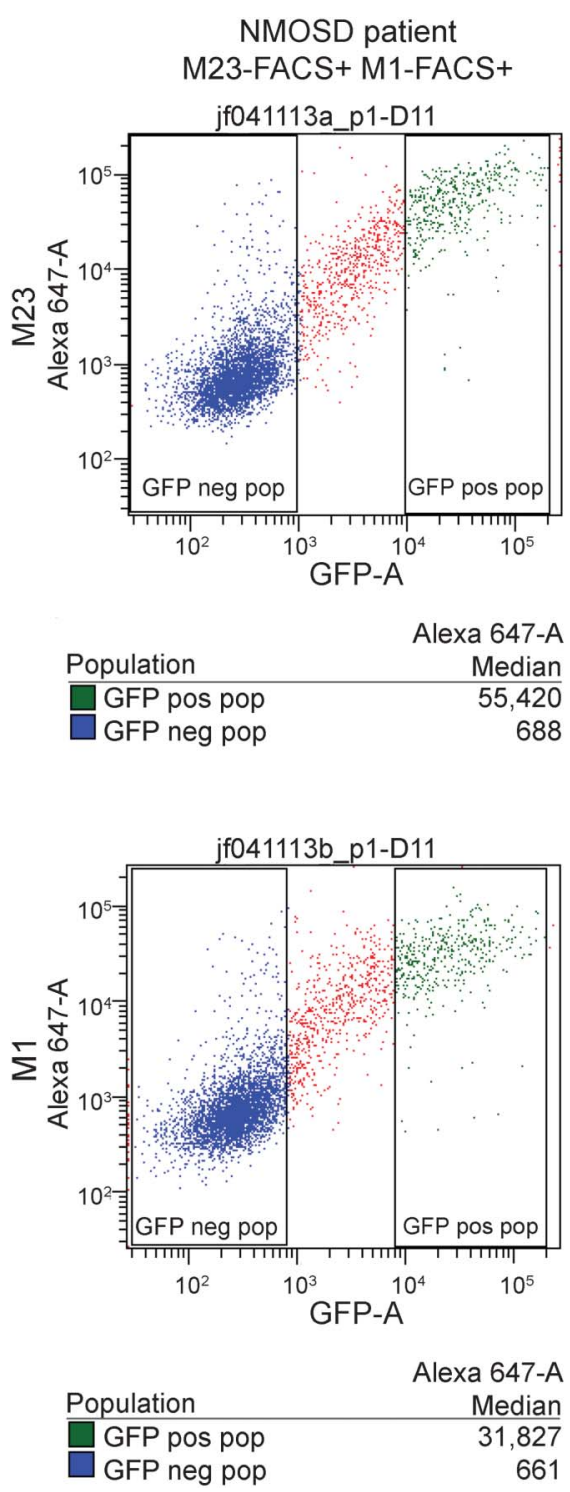

Non-NMOSD patient (MS)

M23-FACS+ M1-FACS-
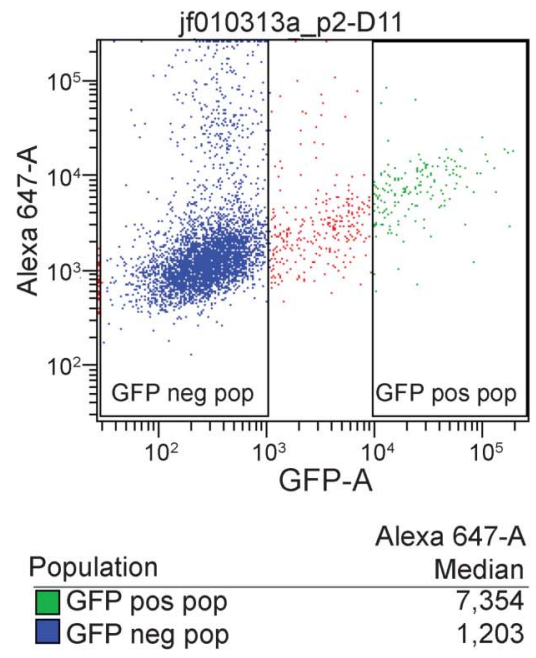

Non-NMOSD patient (MS) M23-FACS- M1-FACS-
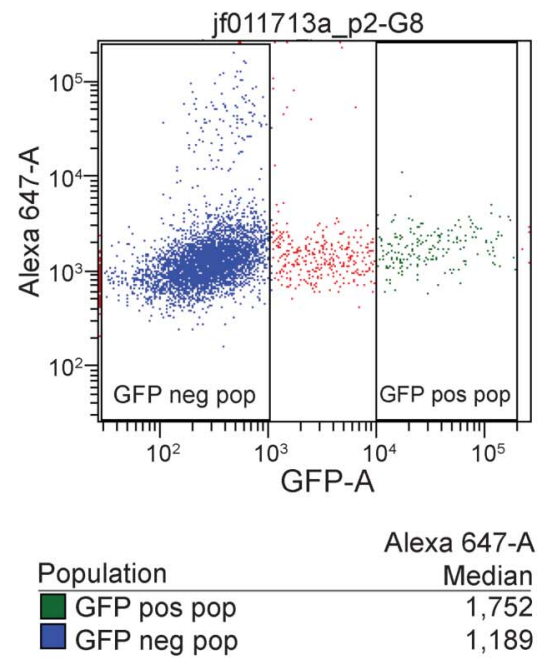
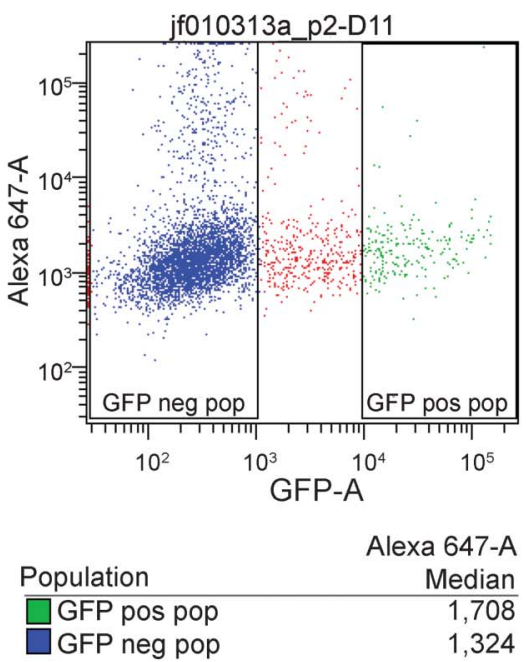
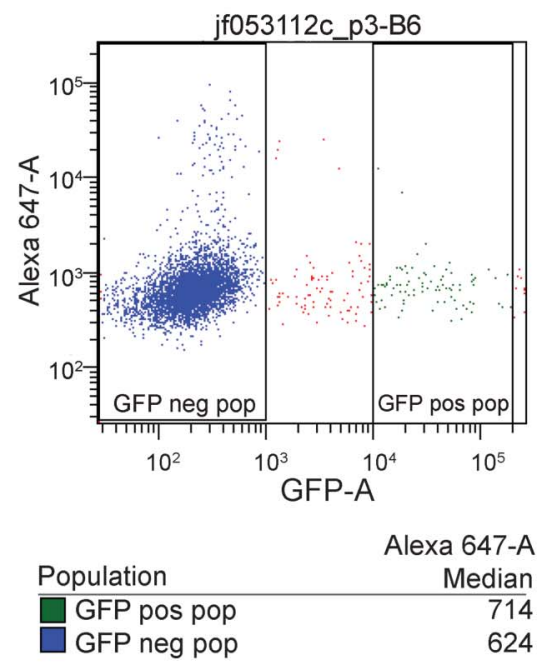

Examples include (from left to right) serum from a patient with neuromyelitis optica spectrum disorder (NMOSD) yielding positivity by both M1-FACS and M23-FACS, serum from a patient with multiple sclerosis (MS) yielding positivity by M23-FACS only, and negative serum from a patient with MS. GFP = green fluorescent protein; pos = positive; pop = population. 
sample buffer (Invitrogen) containing 0.75\% dodecyl- $\beta$-D-maltoside. After clearing debris by centrifugation $\left(20,000 \mathrm{~g}, 10\right.$ minutes, $\left.4^{\circ} \mathrm{C}\right)$, equal amounts of protein (determined by bicinchoninic acid analysis) were mixed with $0.5 \%$ Coomassie Blue G-250 (4:1 ratio) prior to loading on $3 \%-12 \%$ Bis-Tris gel. NativeMark was molecular size standard. After electrophoresis (according to manufacturer instructions), the gels were soaked for 10 minutes in $0.1 \%$ sodium dodecyl sulfate. Separated, minimally denatured proteins were transferred to polyvinylidene fluoride membrane and fixed in $8 \%$ acetic acid. G-250 stain was removed with methanol. Membranes were blocked for 1 hour with $10 \%$ nonfat dry milk in buffer $(20$ mM Tris, pH 7.6, $137 \mathrm{mM}$ sodium chloride, $0.1 \%$ Tween 20 ) and probed with a human AQP4 C-terminus-specific monoclonal mouse IgG (MCM5, produced in-house, 1:2,000 dilution). ${ }^{19}$ After three 5-minute washes (20 mM Tris, pH 7.6, $137 \mathrm{mM}$ sodium chloride, 0.1\% Tween-20), the membranes were exposed to horseradish peroxidase-conjugated goat anti-mouse IgG for 30 minutes (with agitation) and washed again. Bound IgG was detected autoradiographically by enhanced chemiluminescence (Pierce, Rockford, IL).

RESULTS Control subjects. All 338 control subjects were negative by M1-ELISA and M1-CBA. Four sera yielded positive results by $\geq 1$ FACS assays: 2 in the hypergammaglobulinemia group (M23-FACS assay only; IgG binding indices 6.86 and 4.96) and 2 in the ANA-positive non-organ-specific autoimmune group (M23-FACS; IgG binding indices 4.99 and 4.30; 1 was positive also by M1-FACS; IgG binding index 2.74).

Patients with neurologic disorders. Figure 1 illustrates the FACS gating strategy. Figure e-1 at Neurology.org/nn illustrates the distribution of FACS values. Positive results yielded by sera from patients with and without an NMOSD diagnosis are shown in tables 1 and 2. Multiple assays yielded positivity for all but 6 of 45 patients with NMOSDs (table 1). A single assay yielded positivity in all but 3 of 65 patients without NMOSDs (table 2).

Group 1 (consecutive Mayo Clinic patients tested over 5 months). Among 388 sera tested, 34 yielded positive results. Sixteen seropositive patients had an NMOSD diagnosis: NMO, 10; TM, 4 (3 recurrent, 2 longitudinally extensive MRI lesions); ON, 2 (both single attack, 1 bilateral). AQP4-IgG was detected by: M1-FACS, 14 (median value 40.9; range 2.77-138); M23-FACS, 13 (median value 42.1; range 10.4-85.0); M1-CBA, 13 and M1-ELISA, 12 (median value 70.7; range 5.2 to $>160 \mathrm{U} / \mathrm{mL})$.

The remaining 18 sera yielding positive results were from patients who did not have an NMOSD diagnosis (table e-1). AQP4-IgG was detected by: M23-FACS only, 15 (median value 4.04; range 3.01-9.74) and M1-ELISA only, 3 (median 5.4; range $5.20-46.4 \mathrm{U} / \mathrm{mL}$ ).

For clinically defined NMO, assay sensitivities were as follows (table e-2): M1-FACS, 83\%; M23-FACS 75\%; M1-CBA, 75\%; and M1-ELISA, 58\% (differences not statistically significant for all comparisons of M1-FACS

\begin{tabular}{|c|c|c|c|c|c|c|c|}
\hline \multirow[t]{6}{*}{ Table 1} & \multicolumn{7}{|c|}{$\begin{array}{l}\text { Frequency and distribution of positive } \\
\text { results yielded by different AQP4-IgG } \\
\text { assays in patients with clinical NMOSD } \\
\text { diagnosis }\end{array}$} \\
\hline & Assay type & & ults & & & & \\
\hline & M1-ELISA & - & - & - & + & + & + \\
\hline & M1-CBA & - & - & + & + & - & - \\
\hline & M1-FACS & + & + & + & + & - & - \\
\hline & M23-FACS & - & + & + & + & + & - \\
\hline Group 1 & Patients & 1 & 0 & 3 & 10 & 0 & 2 \\
\hline $\mathrm{N}$ tested & 388 & & & & & & \\
\hline Positive & $16(4 \%)$ & & & & & & \\
\hline Group 2 & Patients & 0 & 3 & 3 & 17 & 1 & 0 \\
\hline $\mathrm{N}$ tested & 615 & & & & & & \\
\hline Positive & $24(4 \%)$ & & & & & & \\
\hline Group 3 & Patients & 2 & 1 & 2 & 0 & 0 & 0 \\
\hline $\mathrm{N}$ tested & 31 & & & & & & \\
\hline Positive & 5 (14\%) & & & & & & \\
\hline
\end{tabular}

Abbreviations: AQP4 = aquaporin-4; Ig = immunoglobulin; $\mathrm{NMOSD}=$ neuromyelitis optica spectrum disorder.

Patients with NMOSDs were positive in multiple assays in all but 6 of 45 instances; fluorescence-activated cell sorting (FACS) and cell-based assay (CBA) assays were most sensitive.

to other assays, $p>0.05, \mathrm{McNemar}$ test). Assay specificities for NMO diagnosis were as follows: M1FACS, 100\%; M1-CBA, 100\%; M1-ELISA, 99\%; and M23-FACS, 95\%. M23-FACS was less specific

\begin{tabular}{|c|c|c|c|c|c|}
\hline \multirow[t]{6}{*}{ Table 2} & \multicolumn{5}{|c|}{$\begin{array}{l}\text { Frequency and distribution of positive } \\
\text { results yielded by different AQP4-IgG } \\
\text { assays among patients lacking clinical } \\
\text { evidence of NMOSD diagnosis }\end{array}$} \\
\hline & Assay type & Res & & & \\
\hline & M1-ELISA & - & + & + & - \\
\hline & M1-CBA & - & - & + & t \\
\hline & M1-FACS & - & - & - & t \\
\hline & M23-FACS & + & - & - & t \\
\hline Group 1 & Patients & 15 & 3 & 0 & c \\
\hline $\mathrm{N}$ tested & 388 & & & & \\
\hline Positive & $18(5 \%)$ & & & & \\
\hline Group 2 & Patients & 2 & 2 & 0 & 2 \\
\hline $\mathrm{N}$ tested & 615 & & & & \\
\hline Positive & $6(1 \%)$ & & & & \\
\hline Group 4 & Patients & 0 & 40 & 1 & c \\
\hline $\mathrm{N}$ tested & 41 & & & & \\
\hline Positive & 41 (100\%) & & & & \\
\hline
\end{tabular}

Abbreviations: $\mathrm{AQP} 4$ = aquaporin-4; $\mathrm{CBA}=$ cell-based assay; FACS $=$ fluorescence-activated cell sorting; $\lg =$ immunoglobulin; NMOSD = neuromyelitis optica spectrum disorder.

Patients without NMOSDs were positive in one assay only (ELISA or M23-FACS) in all but 3 of 65 instances. 
than M1-FACS ( $p<0.001$, exact binomial test), M1-CBA $(p<0.001$, exact binomial test), and M1-ELISA ( $p=0.004$, McNemar test). ROC analysis of FACS assays using data for all 50 patients with NMOSD-compatible clinical presentation (NMO, ON, or TM) revealed a significantly larger area under the curve for M1-FACS (0.64) than for M23-FACS (0.57), $p=0.02$ (figure e-2).

Group 2 (AQP4-IgG seropositives among Mayo and non-Mayo tested over 1 month). Thirty sera among 615 tested yielded positive results. For the 24 patients with an NMOSD-compatible clinical diagnosis, AQP4-IgG was detected by: M23-FACS in 24 (median IgG binding index 24.9; range 4.84-52.8); M1-FACS in 23 (median IgG binding index 40.5; range 3.73-88.3);

\section{Figure $2 \quad$ M1 and M23 AQP4 isoforms compared by freeze-fracture electron} microscopic and Western blot analyses
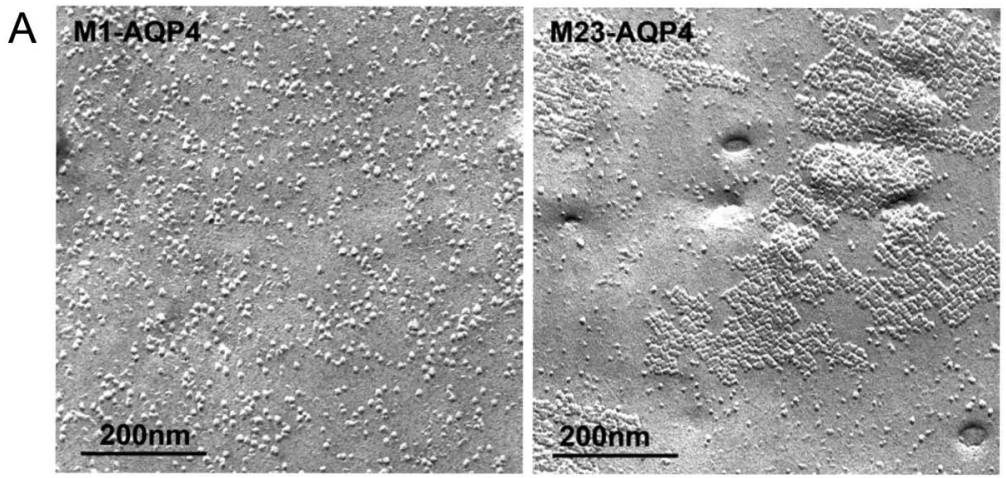

B

AQP4 immunoreactivity

Ratio (M23:M1) $\quad 1: 0 \quad 3: 1 \quad 1: 1 \quad 1: 3 \quad 0: 1$

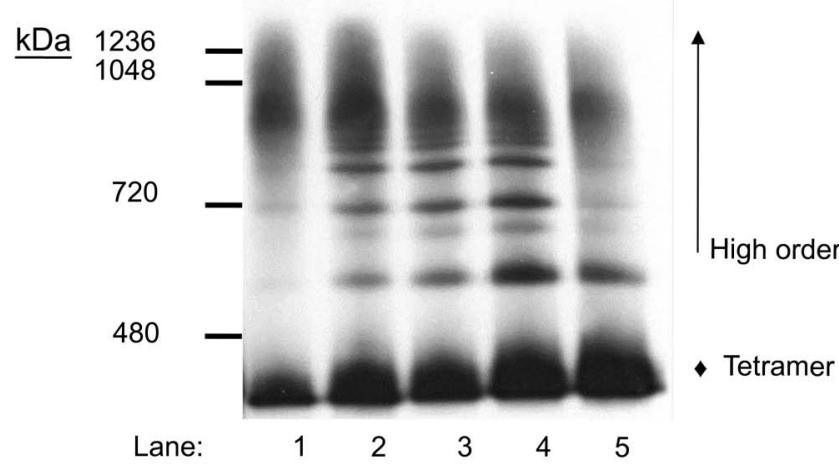

(A) Plasma membranes of HEK293 cells expressing recombinant M1-AQP4 or M23-AQP4 viewed by freeze-fracture electron microscopy. (B) Western blot analysis of the proportion of recombinant AQP4 expressed in higher-order arrays or as tetramers in HEK293 cells transfected with plasmids encoding M23 alone (lane 1), M1 alone (lane 5), or different ratios of each (lanes 2-4). Intramembranous particles in M1-AQP4 cells are predominantly singlet (A, left). Compare the large lattices of orthogonal array-like assemblies in M23-AQP4 cells (A, right). M1-AQP4 coexpression inhibits high-order array formation by M23-AQP4 (B). The $\mathrm{y}$-axis indicates molecular weight $(\mathrm{kDa})$ of AQP4 structures. Solubilized proteins, separated by Blue Native gel electrophoresis and transferred to PDF membrane, were probed with monoclonal AQP4-specific IgG. AQP4 immunoreactivity in largest-sized arrays (lane 1) diminishes with increasing M1:M23 ratio, and the proportion in tetrameric form increases (lane 5). AQP4 = aquaporin-4; lg = immunoglobulin; HEK = human embryonic kidney.
M1-CBA in 20; and M1-ELISA in 18 (median value 40.4; range 8.5 to $>160 \mathrm{U} / \mathrm{mL}$ ).

Six sera yielding a positive result were from patients not considered to have an NMOSD diagnosis. However, 2 patients who were positive by 3 assays (M1-CBA, M1FACS, and M23-FACS) fitted the extended NMOSD spectrum. Both were female and had autoimmune encephalitis. One had coexisting Sjogren syndrome and MRI evidence of MS-atypical brain lesions. The other had optic chiasmitis and a history of metastatic breast carcinoma (without brain metastases), consistent with paraneoplastic NMOSD. ${ }^{20}$ Two others (1 classic MS, the other myelopathy of unknown cause) were positive only by M23-FACS (IgG binding indices 3.97 and 4.95), and another 2 (1 myofascial pain disorder, the other classic MS) were positive only by M1-ELISA (values 5.2 and $107 \mathrm{U} / \mathrm{mL}$ ). Positive likelihood ratios yielded by the 4 assays for groups 1 and 2 combined (with CIs) were as follows: M1-FACS, 65.9 (16.7-267.9); M1-CBA, 54.8 (13.4-224); M1-ELISA, 18.8 (7.5-47-3); and M23FACS, 6.6 (3.9-10.8).

Group 3 (potential falsely seronegative patients). Sera from 31 patients with NMOSD-compatible presentation yielded negative results by M1-ELISA. Five were positive by M1-FACS (median IgG binding index 4.8; range 2.77-6.53); 3 of 5 were also positive by M23FACS (median 10.4; range 6.60-12.1), and 2 were also positive by M1-CBA (table e-3). The remaining 26 , negative by all assays, were judged likely to be true seronegatives.

Group 4 (potential falsely seropositive patients). Among 21,788 individual patients tested, 1,261 yielded positive M1-ELISA results. Physicians caring for 41 of these notified us that they suspected false-positive results because the clinical presentations were not NMOSD-compatible; their median M1-ELISA value was $18.6 \mathrm{IU} / \mathrm{mL}$ (range 5.10 to $>160 \mathrm{IU} / \mathrm{mL}$ ) (table e-4). Only one of these 41 sera yielded a positive result when tested by the 3 CBAs (M1 CBA). The patient had opticospinal symptoms without objective clinical or radiologic abnormalities. The remaining 40 were judged to be false-positives.

Analysis of M1 and M23 AQP4 protein characteristics in transfected HEK293 cells. To analyze differences in the antigenic substrates used in live CBAs (i.e., HEK293 cells transfected with M1 or M23 AQP4 isoform), we compared plasma membrane preparations by freeze-fracture electron microscopy, native gel electrophoresis/Western blot, and flow cytometry. Freeze-fracture images revealed singlet particles in plasma membranes of M1AQP4 cells and large orthogonal array-like assemblies in M23-AQP4 cells (figure 2A). Analysis of plasma membrane proteins solubilized from cells transfected with M1-AQP4 or M23-AQP4 alone, or with both AQP4 isoforms (varying ratios), by Western blot using 
AQP4-specific monoclonal antibody confirmed that the proportion of AQP4 in higher-order assemblies was directly proportional to the transfection ratio of M23: M1 cDNA (figure 2B).

We next tested serum from 16 patients (2 with NMO, 14 without NMOSD) by FACS assays, employing as substrate cells singly transfected with M1-AQP4 or M23-AQP4 or cotransfected with M1-AQP4 and M23-AQP4 (1:1 ratio). All substrates yielded similar results for the 2 control NMO sera (figure 3). IgG binding indices for the 14 non-NMOSD control sera were less than 2.00 for M1 single-transfected cells; for M23 single-transfected cells the median IgG binding index was 6.8 (range 2.98-25.8) and for M1/M23 cotransfected cells the median was 3.3 (range 1.98-14.7).

DISCUSSION This study was prompted by our encountering, through physician consultation, several suspected false-positive and false-negative test results in a clinically validated ELISA kit. We compared the ELISA to 3 alternative AQP4-transfected CBAs suitable for high-throughput clinical testing using patient sera submitted consecutively for AQP4-IgG testing. Previous reports of AQP4-IgG assay performance used selected sera from historical archival cases with an NMOSD-compatible presentation and controls with classic MS or a clinically isolated demyelinating syndrome. Such studies consistently demonstrated high disease specificity for NMOSD and superior sensitivity to tissue-based NMO-IgG immunofluorescence assays. ${ }^{5,8-10,21}$ The results reported here demonstrate the occurrence of falsepositive results, particularly by M1-ELISA and M23-FACS, in sera submitted from nonselected patients in neurologic practice.

Analyses of Mayo Clinic (group 1) patients' sera confirmed the high sensitivity and specificity of CBAs. ${ }^{5}$ Results considered false-positive were encountered in $6 \%$ of sera, but in $95 \%$ of those instances in only 1 assay type (most commonly the live cell-based [FACS] assay employing M23-AQP4-transfected cells or the M1-ELISA). We also reported our broader nonMayo experience. Two of 3 cases from that group yielding positive results by more than 1 CBA (M1FACS, M23-FACS, and M1-CBA) were classified post hoc as having autoimmune AQP4 encephalitis (in 1 with a coexisting autoimmune disease and in the other with breast cancer and optic chiasmitis). Encephalitis is an uncommon but acknowledged manifestation of NMOSD unified by AQP4-IgG positivity and is more common in children than in adults. ${ }^{8,22,23}$ Breast adenocarcinoma is the most common paraneoplastic NMOSD accompaniment. ${ }^{20}$ The third patient (serum positive by both M1-CBA and ELISA but negative by both M1-FACS and M23-FACS) lacked objective

Figure 3 Fluorescence-activated cell sorting (FACS) employing cells singly transfected with M1-AQP4 or M23-AQP4 or cotransfected with both AQP4 isoforms

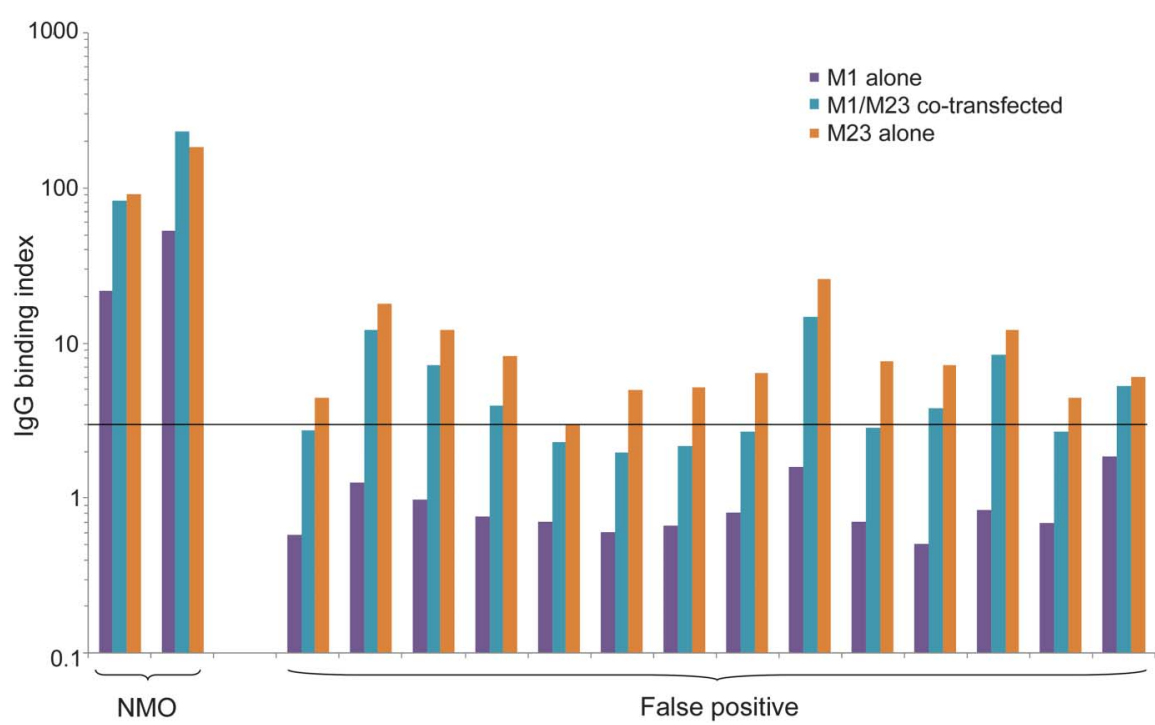

Flow cytometry reveals nonspecific binding of control patients' serum IgG to live HEK293 cells expressing M23-AQP4, which is reduced when M1-AQP4 is coexpressed. IgG in sera of 2 positive control patients with neuromyelitis optica (NMO) binds to all AQP4-transfected cells but binds more avidly to cells expressing M23-AQP4 or both M23 and M1 (1:1 ratio) than to cells expressing M1 alone. IgG binding indices for the 14 control sera lacking NMOSD were all less than 2.00 for M1 single-transfected cells; for M23 single-transfected cells the median IgG binding index was 6.8 (range 2.98-25.8) and for M1/M23 cotransfected cells the median was 3.3 (range 1.98-14.7). The horizontal gray line indicates the cutoff for M23FACS positivity (3.00). AQP4 = aquaporin-4; Ig = immunoglobulin; HEK = human embryonic kidney; NMOSD = NMO spectrum disorder. 
abnormalities, despite opticospinal symptoms. It is conceivable that this serum contained nonpathogenic IgG specific for an intracellular AQP4 epitope, inaccessible in live transfected cells. To clarify the clinical diagnosis, it is cost-effective to test by additional AQP4-IgG assays for the few suspected false-positive results encountered.

ELISA assays are prone to interference from nonspecific antibody binding. ${ }^{24}$ All control sera yielding false-positive results in M23-FACS assays were from ANA-positive or hypergammaglobulinemic patients. That observation led us to suspect promiscuous binding of IgG to high-order M23-AQP4 arrays, which confer adhesive properties. ${ }^{25}$ It is recognized that antigen-specific binding of NMO-IgG to M23AQP4 is more avid than NMO-IgG binding to M1AQP4 ${ }^{26}$ (due to closer proximity of epitopes in highorder arrays ensuring bivalent engagement of both Fabs). The mechanism by which nonspecific IgG bound preferentially to M23-AQP4 is unknown. The microenvironment of large M23-AQP4 arrays with localized water molecules might promote nonspecific IgG binding through increased hydrogen bonding. ${ }^{27,28}$ Supporting this hypothesis, we found instances of non-NMOSD patient IgG binding to live M23AQP4 cells, but not to live M1-AQP4 cells, and an M1-AQP4 dose-dependent reduction in binding to M1/M23 cotransfected cells. ${ }^{14,15,18}$

The high number of potential false-positive results encountered reflects the large numbers acquired in a high-volume clinical service laboratory. In case-control studies, controls are generally matched by age and sex to cases in a 1:1 ratio. In contrast, the control to case ratio in our study's group 1 was 8:1. In clinical practice, neurologists customarily order AQP4-IgG testing for patients with varying pretest probabilities for NMOSD diagnosis. An inverse relationship exists between the proportion of patients without NMOSD in the tested cohort and the proportion of positive results determined to be true positives. Thus, even assays with reported $100 \%$ specificity among research cohorts will yield unanticipated positive results in clinical service. Continuous service-based quality assurance is critical.

For patients with suspected NMOSD, serologic testing for AQP4-IgG aids confirmation of the diagnosis. Live CBAs, particularly those using the M1AQP4 isoform as antigen, had the best performance characteristics in our experience.

\section{AUTHOR CONTRIBUTIONS}

Mr. Fryer: analysis and interpretation of data, drafting of manuscript. Dr. Lennon: study concept and design, analysis and interpretation of data, critical revision of manuscript, study supervision. Dr. Pittock: analysis and interpretation of data, critical revision of manuscript. Ms. Jenkins: statistical analyses, critical revision of manuscript. Dr. Fallier-Becker: analysis and interpretation of data, critical revision of manuscript. Dr. Clardy: analysis and interpretation of data. Dr. Horta: analysis and interpretation of data. Mr. Jedynak: analysis and interpretation of data. Dr. Lucchinetti: analysis and interpretation of data. Dr. Shuster: analysis and interpretation of data. Dr. Weinshenker: analysis and interpretation of data, critical revision of manuscript. Dr. Wingerchuk: analysis and interpretation of data, critical revision of manuscript. Dr. McKeon: study concept and design, analysis and interpretation of data, drafting of manuscript, critical revision of manuscript, study supervision.

\section{ACKNOWLEDGMENT}

The authors thank Ms. Eva-Maria Knittel, MS, for excellent technical support.

\section{STUDY FUNDING}

The study was supported by the NIH (NS065829) and The GuthyJackson Foundation.

\section{DISCLOSURE}

J.P. Fryer reports no disclosures. V.A. Lennon receives royalties for technology relating to AQP4 antibodies for diagnosis of NMO; is a named inventor on filed patents that relate to functional AQP4/ NMO-IgG assays and NMO-IgG as a cancer marker; and receives research support from the NIH (NS065829). S.J. Pittock is a named inventor on filed patents that relate to functional AQP4/NMO-IgG assays and NMO-IgG as a cancer marker and receives research support from the NIH (NS065829), the Guthy-Jackson Charitable Foundation, and Alexion Pharmaceuticals, Inc. S.M. Jenkins, P. FallierBecker, and S.L. Clardy report no disclosures. E. Horta has received research support from the Multiple Sclerosis International Foundation. E.A. Jedynak reports no disclosures. C.F. Lucchinetti shares in royalties from marketing of kits for detecting AQP4 autoantibody and from the sale of Blue Books of Neurology: Multiple Sclerosis 3 (Saunders Elsevier, 2010); has received travel funding from Biogen Idec; and receives research support from the NIH (RO1-NS49577), the Guthy-Jackson Charitable Foundation, and the National Multiple Sclerosis Society (RG 3185-B-3). E.A. Shuster receives research support from the National Multiple Sclerosis Society. B.G. Weinshenker serves on data safety monitoring boards for Novartis, Biogen Idec, and Mitsubishi; serves on adjudication panel for Medimmune; has received payment for consultation from Elan Pharmaceuticals, GlaxoSmithKline Pharmaceuticals, Ono Pharmaceuticals, CHORD Therapeutics, and Chugai Pharmaceuticals; serves on the editorial boards of the Canadian Journal of Neurological Sciences, Neurology, and the Turkish Journal of Neurology; received research support from the Guthy-Jackson Charitable Foundation; receives license royalties from RSR Ltd. for a patent regarding AQP4-associated antibodies for diagnosis of neuromyelitis optica; and has consulted for Elan, GlaxoSmithKline, Ono, Asahi Kasei Medical Company, Chugai, Alexion, and Chord. D.M. Wingerchuk has received research support from Genentech, Genzyme, TerumoBCT, and the National Multiple Sclerosis Society; has served as a consultant to Chugai Pharmaceuticals, Alexion, and MedImmune, Inc.; and is on the editorial board for Current Medical Research and Opinion and Drugs in Context. A. McKeon receives research support from the Guthy Jackson Charitable Foundation and MedImmune, Inc. Go to Neurology.org/nn for full disclosures.

Received January 20, 2014. Accepted in final form March 31, 2014.

\section{REFERENCES}

1. Apiwattanakul M, Popescu BF, Matiello M, et al. Intractable vomiting as the initial presentation of neuromyelitis optica. Ann Neurol 2010;68:757-761.

2. Iorio R, Lucchinetti CF, Lennon VA, et al. Syndrome of inappropriate antidiuresis may herald or accompany neuromyelitis optica. Neurology 2011;77:1644-1646.

3. Weinshenker BG, Wingerchuk DM, Vukusic S, et al. Neuromyelitis optica IgG predicts relapse after longitudinally extensive transverse myelitis. Ann Neurol 2006;59:566-569.

4. Wingerchuk DM, Pittock SJ, Lucchinetti CF, Lennon VA, Weinshenker BG. A secondary progressive clinical course is uncommon in neuromyelitis optica. Neurology 2007;68: 603-605. 
5. Waters PJ, McKeon A, Leite MI, et al. Serologic diagnosis of NMO: a multicenter comparison of aquaporin-4-IgG assays. Neurology 2012;78:665-671; discussion 669.

6. Sato DK, Nakashima I, Takahashi T, et al. Aquaporin-4 antibody-positive cases beyond current diagnostic criteria for NMO spectrum disorders. Neurology 2013;80:2210-2216.

7. McKeon A, Fryer JP, Apiwattanakul M, et al. Diagnosis of neuromyelitis spectrum disorders: comparative sensitivities and specificities of immunohistochemical and immunoprecipitation assays. Arch Neurol 2009;66:1134-1138.

8. Apiwattanakul M, Asawavichienjinda T, Pulkes T, et al. Diagnostic utility of NMO/AQP4-IgG in evaluating CNS inflammatory disease in Thai patients. J Neurol Sci 2012; 320:118-120.

9. Jarius S, Frederikson J, Waters P, et al. Frequency and prognostic impact of antibodies to aquaporin- 4 in patients with optic neuritis. J Neurol Sci 2010;298:158-162.

10. Marignier R, Bernard-Valnet R, Giraudon P, et al. Aquaporin-4 antibody-negative neuromyelitis optica: distinct assay sensitivity-dependent entity. Neurology 2013;80:2194-2200.

11. Jiao Y, Fryer JP, Lennon VA, et al. Updated estimate of AQP4-IgG serostatus and disability outcome in neuromyelitis optica. Neurology 2013;81:1197-1204.

12. Yang B, Ma T, Verkman AS. cDNA cloning, gene organization, and chromosomal localization of a human mercurial insensitive water channel. Evidence for distinct transcriptional units. J Biol Chem 1995;270:22907-22913.

13. Rash JE, Davidson KG, Yasumura T, Furman CS. Freeze-fracture and immunogold analysis of aquaporin-4 (AQP4) square arrays, with models of AQP4 lattice assembly. Neuroscience 2004;129:915-934.

14. Furman CS, Gorelick-Feldman DA, Davidson KG, et al. Aquaporin-4 square array assembly: opposing actions of M1 and M23 isoforms. Proc Natl Acad Sci U S A 2003; 100:13609-13614.

15. Crane JM, Verkman AS. Determinants of aquaporin-4 assembly in orthogonal arrays revealed by live-cell single-molecule fluorescence imaging. J Cell Sci 2009;122:813-821.

16. Wingerchuk DM, Lennon VA, Pittock SJ, Lucchinetti CF, Weinshenker BG. Revised diagnostic criteria for neuromyelitis optica. Neurology 2006;66:1485-1489.
17. R Development Core Team. R: A Language and Environment for Statistical Computing. Vienna, Austria: R Foundation for Statistical Computing; 2010. Available at: http://www.R-project.org/, ISBN 3-900051-07-0.

18. Iorio R, Fryer JP, Hinson SR, et al. Astrocytic autoantibody of neuromyelitis optica (NMO-IgG) binds to aquaporin-4 extracellular loops, monomers, tetramers and high order arrays. J Autoimmun 2013;40:21-27.

19. Hinson SR, Romero MF, Popescu BF, et al. Molecular outcomes of neuromyelitis optica (NMO)-IgG binding to aquaporin-4 in astrocytes. Proc Natl Acad Sci U S A 2012; 109:1245-1250.

20. Pittock SJ, Lennon VA. Aquaporin-4 autoantibodies in a paraneoplastic context. Arch Neurol 2008;65:629-632.

21. Takahashi T, Fujihara K, Nakashima I, et al. Establishment of a new sensitive assay for anti-human aquaporin- 4 antibody in neuromyelitis optica. Tohoku J Exp Med 2006; 210:307-313.

22. McKeon A, Lennon VA, Lotze T, et al. CNS aquaporin-4 autoimmunity in children. Neurology 2008;71:93-100.

23. Nakamura M, Misu T, Fujihara K, et al. Occurrence of acute large and edematous callosal lesions in neuromyelitis optica. Mult Scler 2009;15:695-700.

24. Remaley A, Hortin GL. Protein analysis for diagnostic applications. In: Detrick B, Hamilton RG, Folds JD, editors. Manual of Molecular and Clinical Laboratory Immunology. Washington, DC: ASM Press; 2006:17-18.

25. Hiroaki Y, Tani K, Kamegawa A, et al. Implications of the aquaporin- 4 structure on array formation and cell adhesion. J Mol Biol 2006;355:628-639.

26. Crane JM, Lam C, Rossi A, Gupta T, Bennett JL, Verkman AS. Binding affinity and specificity of neuromyelitis optica autoantibodies to aquaporin-4 M1/M23 isoforms and orthogonal arrays. J Biol Chem 2011;286: 16516-16524.

27. Braden BC, Poljak RJ. Structural features of the reactions between antibodies and protein antigens. FASEB J 1995;9: 9-16.

28. Mohan S, Kourentzi K, Schick KA, et al. Association energetics of cross-reactive and specific antibodies. Biochemistry 2009;48:1390-1398. 


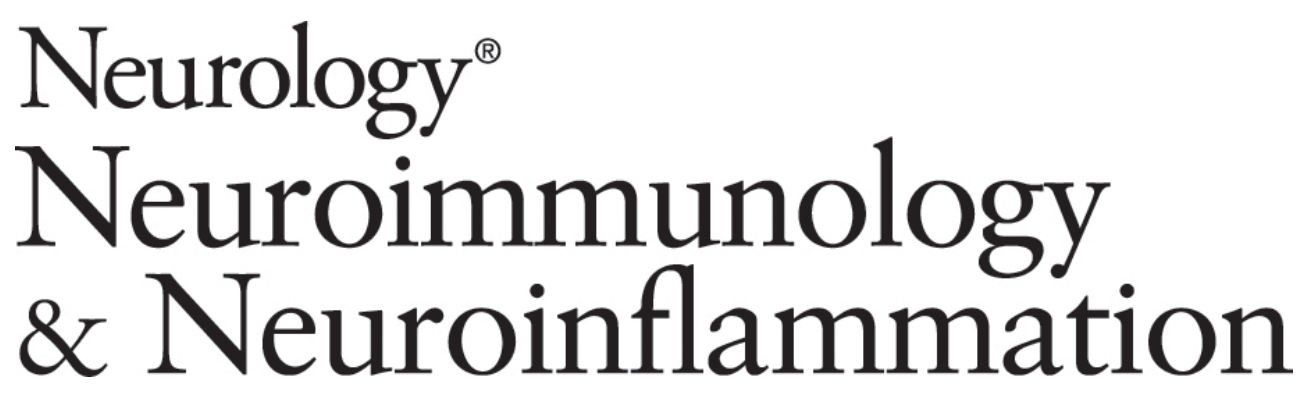

AQP4 autoantibody assay performance in clinical laboratory service

J.P. Fryer, V.A. Lennon, S.J. Pittock, et al.

Neurol Neuroimmunol Neuroinflamm 2014;1;

DOI 10.1212/NXI.0000000000000011

This information is current as of May 22, 2014

Neurol Neuroimmunol Neuroinflamm is an official journal of the American Academy of Neurology.

Published since April 2014, it is an open-access, online-only, continuous publication journal. Copyright $($ ) 2014 American Academy of Neurology. All rights reserved. Online ISSN: 2332-7812.

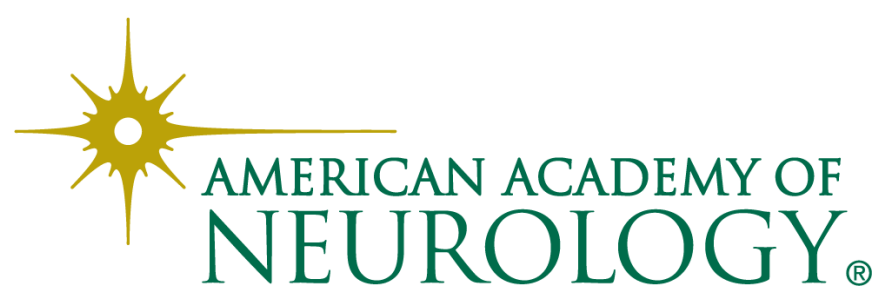




\section{Updated Information \& Services}

\section{Supplementary Material}

\section{References}

Citations

Subspecialty Collections

Permissions \& Licensing

Reprints including high resolution figures, can be found at: http://nn.neurology.org/content/1/1/e11.full.html

Supplementary material can be found at: http://nn.neurology.org/content/suppl/2014/05/22/1.1.e11.DC1

This article cites 26 articles, 5 of which you can access for free at: http://nn.neurology.org/content/1/1/e11.full.html\#\#ref-list-1

This article has been cited by 6 HighWire-hosted articles: http://nn.neurology.org/content/1/1/e11.full.html\#\#otherarticles

This article, along with others on similar topics, appears in the following collection(s):

All Demyelinating disease (CNS)

http://nn.neurology.org//cgi/collection/all_demyelinating_disease_cns Autoimmune diseases

http://nn.neurology.org//cgi/collection/autoimmune_diseases Devic's syndrome

http://nn.neurology.org//cgi/collection/devics_syndrome Optic neuritis; see Neuro-ophthalmology/Optic Nerve http://nn.neurology.org//cgi/collection/optic_neuritis Transverse myelitis

http://nn.neurology.org//cgi/collection/transverse_myelitis

Information about reproducing this article in parts (figures,tables) or in its entirety can be found online at:

http://nn.neurology.org/misc/about.xhtml\#permissions

Information about ordering reprints can be found online: http://nn.neurology.org/misc/addir.xhtml\#reprintsus

Neurol Neuroimmunol Neuroinflamm is an official journal of the American Academy of Neurology.

Published since April 2014, it is an open-access, online-only, continuous publication journal. Copyright $\odot$ 2014 American Academy of Neurology. All rights reserved. Online ISSN: 2332-7812.

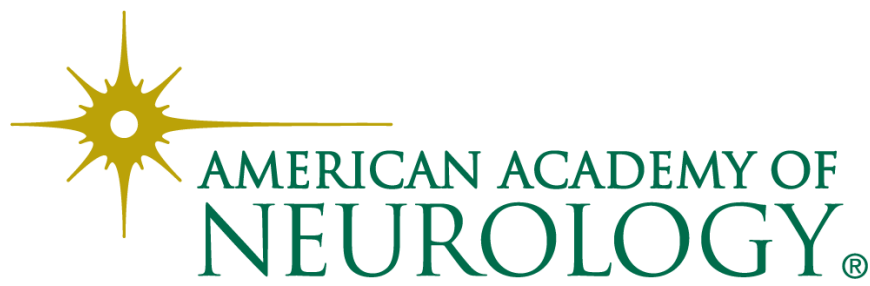

